\title{
Novel Somatic Copy Number Alteration Identified for Cervical Cancer in the Mexican American Population
}

\author{
Alireza Torabi ${ }^{1}$, Javier Ordonez ${ }^{2}$, Brenda Bin Su ${ }^{4}$, Laura Palmer ${ }^{3}$, Chunxiang Mao ${ }^{3}$, \\ Katherine E. Lara ${ }^{3}$, Lewis P. Rubin ${ }^{3}$ and Chun $\mathrm{Xu}^{3, *}$ \\ 1 Department of Pathology, TTUHSC, El Paso 79905, TX, USA; alireza.torabi@ttuhsc.edu \\ 2 Department of Biomedical Science, TTUHSC, El Paso 79905, TX, USA; jaordonez2003@gmail.com \\ 3 Department of Pediatrics, Texas Tech University Health Sciences Center (TTUHSC), El Paso 79905, TX, USA; \\ laura.palmer@ttuhsc.edu (L.P.); frankmao2007@gmail.com (C.M.); kelara@miners.utep.edu (K.E.L.); \\ lewis.rubin@ttuhsc.edu (L.P.R.) \\ 4 Department of Internal Medicine, College of Medicine and Health Sciences, UAE University, \\ Al-Ain 15551, UAE; brendabinsu@uaeu.ac.ae \\ * Correspondence: chun.xu@ttuhsc.edu; Tel.: +915-215-4196 \\ Academic Editor: Sibaji Sarkar \\ Received: 1 June 2016; Accepted: 25 July 2016; Published: 3 August 2016
}

\begin{abstract}
Cervical cancer affects millions of Americans, but the rate for cervical cancer in the Mexican American is approximately twice that for non-Mexican Americans. The etiologies of cervical cancer are still not fully understood. A number of somatic mutations, including several copy number alterations (CNAs), have been identified in the pathogenesis of cervical carcinomas in non-Mexican Americans. Thus, the purpose of this study was to investigate CNAs in association with cervical cancer in the Mexican American population. We conducted a pilot study of genome-wide CNA analysis using 2.5 million markers in four diagnostic groups: reference $(n=125)$, low grade dysplasia (cervical intraepithelial neoplasia (CIN)-I, $n=4)$, high grade dysplasia (CIN-II and -III, $n=5$ ) and invasive carcinoma (squamous cell carcinoma (SCC), $n=5$ ) followed by data analyses using Partek. We observed a statistically-significant difference of CNA burden between case and reference groups of different sizes $(>100 \mathrm{~kb}, 10-100 \mathrm{~kb}$ and $1-10 \mathrm{~kb}$ ) of CNAs that included deletions and amplifications, e.g., a statistically-significant difference of $>100 \mathrm{~kb}$ deletions was observed between the reference (6.6\%) and pre-cancer and cancer (91.3\%) groups. Recurrent aberrations of 98 CNA regions were also identified in cases only. However, none of the CNAs have an impact on cancer progression. A total of 32 CNA regions identified contained tumor suppressor genes and oncogenes. Moreover, the pathway analysis revealed endometrial cancer and estrogen signaling pathways associated with this cancer $(p<0.05)$ using Kyoto Encyclopedia of Genes and Genomes (KEGG). This is the first report of CNAs identified for cervical cancer in the U.S. Latino population using high density markers. We are aware of the small sample size in the study. Thus, additional studies with a larger sample are needed to confirm the current findings.
\end{abstract}

Keywords: cervical cancer; copy number alterations; genome wide analysis; somatic; Mexican American population; Illumina HumanOmni2.5-8 BeadChip

\section{Introduction}

Based on the U.S. Centers for Disease Control and Prevention (CDC) 2009 report, 12,357 women were diagnosed with cervical cancer, and 3909 women died from cervical cancer in the United States. This huge number of patients with cervical cancer has been a critical issue and is responsible for $10 \%-15 \%$ of cancer-related deaths in females globally [1]. Cervical cancer is the second most common malignant tumor in women worldwide. Among these tumors, approximately $80 \%$ are squamous cell 
carcinomas (SCCs), and 5\%-20\% are adenocarcinomas (AdCAs) [2,3]. Cervical SCCs are developed from a premalignant disease known as cervical intraepithelial neoplasia (CIN) Graded 1-3 with increasing atypical features. The five-year overall survival for cervical cancer is only $66 \%$.

In addition, increasing evidence suggests that infection with high-risk subtypes of human papillomavirus (HPV) (e.g., HPV-16 and HPV-18) is the most common cause and is the primary initiator of premalignant lesions [4]. However, only a small proportion of women infected with oncogenic HPV subtypes develop cervical cancer, which suggests that HPV infection alone is insufficient to cause cancer, and there is a possibility of other host factors linked to the development of invasive cervical cancer [5], like genetic variation, including polymorphisms, insertions or deletions in the host genome [6,7]. Increasing evidence demonstrates that there was a consistent relationship between certain genetic variants (such as the tumor protein 53 (TP53) Arg72Pro polymorphism) and cervical cancer, most likely modulated by the presence of high-risk HPV during progression from squamous intraepithelial lesions (SIL) to cervical cancer.

Moreover, Mexican American women in Texas have among the highest rates of cervical cancer incidence and mortality in the country [8] with twice the frequency as compared to their non-Mexican American counterparts. The annual death rate from cervical cancer for Mexican Americans is 24.2 out of 100,000 [9]. However, there is a lack of studies on somatic mutation identification for cervical cancer in this population. Only four studies have reported on genetic basis of cervical cancer in Mexican American women based on a PubMed search (19 November 2015). The number of the Mexican American population was estimated at 50.5 million in the 2010 census, making Mexican American the largest minority group in the U.S., as well as a rapidly growing segment of the U.S. population.

Recent advances in genome studies have led to the discovery of one important type of variation that can be assessed with recent technology: copy number alterations (CNAs), usually for a cancer study, somatic copy number changes and/or copy number variations (CNVs), usually for a non-cancer study, or germline copy number changes, such as CNVs identified for neuropsychiatric disorders in our recent study [10]. These CNAs or CNVs are by definition chromosomal regions with sizes of $1 \mathrm{~kb}$ to several $\mathrm{Mb}$, which vary across individuals with regard to the number of copies of a chromosomal segment. CNVs refer to structural variations of the DNA that include insertions, deletions and duplications. Studies have found that CNVs cover as much as $14 \%$ of the human genome [11], and there is a much higher de novo rate as many as 10-1000-fold in CNVs as compared to single nucleotide polymorphisms (SNPs) [11,12]. Furthermore, CNVs have been shown to account for more genomic differences between individuals than SNPs $[13,14]$. Therefore, CNVs may contribute a sizeable amount of disease phenotypic variation in each individual of a population [15].

Analyses integrating mutation information with data on rearrangements and CNAs have revealed a higher-order organization of the seemingly random genetic events that lead to cancer [16]. Interestingly, genes in regions subject to copy number changes appear to be organized along functional ontological terms related to cancer [16]. Studies have also implicated a number of somatic mutations, including TP53, phosphatidylinositol-4,5-bisphosphate 3-kinase catalytic subunit alpha (PIK3CA), phosphatase and tensin homolog (PTEN), serine/threonine kinase 11 (STK11) and V-Ki-ras2 Kirsten rat sarcoma viral oncogene homolog $(K R A S)[17,18]$, and several CNAs in the pathogenesis of cervical carcinomas $[19,20]$ in non-Mexican Americans.

In this study, we carried out a genome-wide survey of potential somatic CNAs, including amplifications and deletions, in apparently normal tissues $(n=2)$, low grade dysplasia $(n=4)$, high grade dysplasia $(n=5)$, invasive carcinoma $(n=5)$ and blood samples $(n=125$, serving as a reference group) of female subjects from the HapMap data. We are aware of the limited number of cases and the lack of a control group. Thus, in the future, a large study with a control sample and more cases as a methodological alternative is needed. We genotyped 2.5 million markers and analyzed somatic CNAs in a total of 14 tissues using the Illumina HumanOmni2.5-8 BeadChip Kit at tissue-level resolution. We mapped genomic changes: (1) between peripheral blood samples of the reference subjects and cervical tissues from the cases (cervical dysplasia and invasive carcinoma); because only 
two normal cervical tissue samples had insufficient statistical power, we excluded these two samples from the further analysis; (2) we also analyzed genomic changes among four diagnostic groups (normal, low, high grade and invasive carcinoma). We expect that this study: (i) will provide an estimate of the prevalence of somatic CNAs by identifying specific patterns, genes and/or biological pathways associated with different stages of cervical dysplasia in Mexican Americans; (ii) will investigate the genomic context of these somatic CNAs; and (iii) will evaluate whether the burden of somatic mutations predicts tumor progression.

\section{Materials and Methods}

\subsection{Materials}

A total of 14 tissues (low, high grade dysplasia and invasive carcinoma) from cases and 125 female subjects, serving as a reference group, were used for this study. The demographic information is shown in Table 1. The cases were categorized into three groups, including low grade dysplasia (CIN-I, $n=4)$, high grade dysplasia (CIN-II and III, $n=5$ ) and squamous cell carcinoma (SCC, $n=5$ ) groups. For a broader definition of the case group, we also divided the cases into two groups, pre-cancer (CIN-I, -II and -III) and cancer (SCC). All of the case subjects in the current study were from the Mexican American population recruited from the outpatient clinics at the University Medical Center (UMC) and Texas Tech University Health Sciences Center (TTUHSC)-El Paso. All cases of cervical cancer were diagnosed as SCC by histopathological examinations, whereas healthy women had no abnormal cytological findings in the Pap smear tests of the uterine cervix.

Table 1. Clinical demographics with diagnosis, age for cases and reference subjects.

\begin{tabular}{ccccc}
\hline Subject ID & Age (years) & Diagnosis 1 & Diagnosis 2 & Diagnosis 3 \\
\hline 14 & 42 & CIN-I & low grade dysplasia & pre-cancer \\
16 & 24 & CIN-I & low grade dysplasia & pre-cancer \\
17 & 53 & CIN-I & low grade dysplasia & pre-cancer \\
15 & 31 & CIN-I & low grade dysplasia & pre-cancer \\
12 & 27 & CIN-II & high grade dysplasia & pre-cancer \\
8 & 39 & CIN-III & high grade dysplasia & pre-cancer \\
11 & 21 & CIN-III & high grade dysplasia & pre-cancer \\
6 & 30 & CIN-III & high grade dysplasia & pre-cancer \\
5 & 38 & CIN-III & high grade dysplasia & pre-cancer \\
3 & 55 & SCC & SCC & SCC \\
4 & 44 & SCC & SCC & SCC \\
2 & 51 & SCC & SCC & SCC \\
7 & 31 & SCC & SCC & SCC \\
1 & 42 & SCC & SCC & SCC \\
$n=125$ females & NA & reference & reference & reference \\
\hline
\end{tabular}

All subjects in the cases were human papillomavirus (HPV) positive and from the Mexican American population. Reference subjects were from an admixed population. NA, not available. CIN, cervical intraepithelial neoplasia; SCC, squamous cell carcinoma.

The Illumina HumanOmni2.5-8 BeadChip data from a total of 125 blood samples of female subjects from the HapMap were used as a reference in the current study.

\subsection{Methods}

\subsubsection{Tissue Specimens}

Sixteen cervical tissue samples were obtained from the Department of Pathology, TTUHSC-El Paso. We excluded two normal tissues due to an insufficient tissue sample size. All case subjects were HPV positive, from the Mexican American population and had signed Institutional Review Board-approved written informed consent forms prior to enrolling in the study. The procedures were 
approved by the Institutional Review Boards of TTUHSC (IRB \#E13107), and the study was performed in accordance with the Helsinki Declaration of 1975.

\subsubsection{Microdissection}

Paraffin-embedded tissues were first sectioned into 10- $\mu$ m slices, which were hematoxylin-eosin stained for the selection of the appropriate tissue area. The corresponding selected areas of each tissue sample were then collected under microscopic observation with a 30-gauge needle (Becton-Dickinson, Franklin Lakes, NJ, USA).

Genomic DNA of micro-dissected tissue was extracted by proteinase K digestion followed by standard phenol-chloroform extraction. The QIAamp Formalin-Fixed, Paraffin-Embedded (FFPE) Tissue Kit from Qiagen (Valencia, CA, USA), which is widely used for extracting DNA from FFPE sections, was used. The experiment was performed according to the manufacturer's handbook. The total amount of DNA was spectrophotometrically determined by measuring the absorbance at $260 \mathrm{~nm}$ (A260), and DNA purity was assessed by detecting the A260/A280 ratio using the Varioskan Flash (Thermo Scientific, Rockford, IL, USA) according to the manufacturer's instructions.

\subsubsection{High Density Genotyping}

Genomic DNA from the case group was used to obtain genotypes by the Illumina HumanOmni2.5-8 BeadChip (Illumina, San Diego, CA, USA). This DNA chip provided over 2.5 million markers at a median spacing of $1.2 \mathrm{~kb}$ and full support of CNV or CNA applications, which was a powerful genotyping tool and allowed us to make more meaningful discoveries. Genomic annotations were based on National Center for Biotechnology Information (NCBI) Human Genome Build 37 (University of California, Santa Cruz Genome Browser Release 19), and genotyping experiments were performed at the Genomics Core at the TTUHSC-El Paso.

Due to our limited number of control samples of cervical tissues, we used publicly available HapMap data with genotypes, including CNV data of the same DNA chip, the Illumina HumanOmni2.5-8 BeadChip Kit, in the 125 female subjects as a reference group. The HapMap data with genotypes were downloaded from [21].

In addition, there is no genotype data available for the Mexican American population using the HapMap data, so we selected these 125 female subjects from the Admix populations (Utah residents with Northern and Western European ancestry, CEU; Yoruba, YRI; Han Chinese, CHB, and Japanese, JPT) since the various combinations of reference panels with the multi-ethnic populations had better accuracy than those containing only single ethnic samples [22] for genetic study and genetic imputation analysis.

The raw genotyping signal data were processed by the Illumina GenomeStudio software Genotyping Module Version 3.2.33 (Illumina) and converted to allele-specific intensity values. The genotype call rate threshold was set at $\geqslant 95 \%$ for all samples, and a total of 139 including case $(n=14)$ and reference $(n=125)$ subjects passed the quality control. A Partek customized report of the normalized genotype data, composed of those 139 samples, including low grade (CIN-I $=4)$, high grade (CIN-II and CIN-III = 5), SCC $(n=5)$ and 125 females from the reference group (Table 1$)$, was transferred to Partek ${ }^{\circledR}$ Genomic Suite ${ }^{\circledR}$ software, Version 6.6, Copyright 2014, Partek Inc. (Saint Louis, MO, USA), for downstream analysis.

\subsubsection{CNA Detection}

Unpaired copy number analysis was performed in the Partek Genomics Suite comparing allele intensities to a reference baseline of 125 female HapMap admixed samples using a similar analysis strategy as a previous publication [23]. The genomic segmentation algorithm was applied to find break points and to detect amplifications (gains) and deletions (losses). The following stringent parameters were used to identify CNAs and CNA regions as a previous study [24]: (1) each segment must contain a minimum of 10 consecutive filtered probe sets; (2) a $p$ value threshold of 0.001 when compared to 
the neighboring adjacent regions; and (3) a signal-to-noise threshold of 0.5 and diploid copy number 1.7 to 2.3 .

\subsubsection{Pathway Analysis}

We further examined whether these CNAs in the various genes have an impact on gene functions. Gene ontology (GO) analysis was also performed using the Partek ${ }^{\circledR}$ Genomic Suite ${ }^{\circledR}$ software, Version 6.6, Copyright ${ }^{\circledR}$ 2014, Partek Inc., to investigate whether there was enrichment for cancer-associated CNAs $(p<0.05)$ in genes from any ontology categories.

Disease association of individual CNA frequencies with patients, as a group, compared to a reference group, was assessed using $2 \times 2$ or $2 \times 3$ contingency tables, two-tailed $\chi^{2}$ tests or Fisher exact tests. Statistical analyses were performed using the SPSS statistical software package (Version 10, IBM, Chicago, IL, USA). Differences with two-tailed probability values of $p \leqslant 0.05$ were taken as statistically significant. $p$-values for tests of CNA association were conservatively corrected for multiple testing using the Bonferroni method.

\section{Results}

\subsection{Overall CNA Patterns}

We processed genotype and intensity data for all 2.5 million probes of the Illumina HumanOmni2.5-8 BeadChip Kit for the 14 cases and 125 reference subjects. A number of CNAs (deletions or losses) was present in many chromosomal regions (Figure 1). A total of 2220 CNAs $>1000$ bp was identified, including 725 (32.7\%) amplifications (gains) and 1495 (67.3\%) deletions (losses) mainly on the 22 autosomal chromosomes.

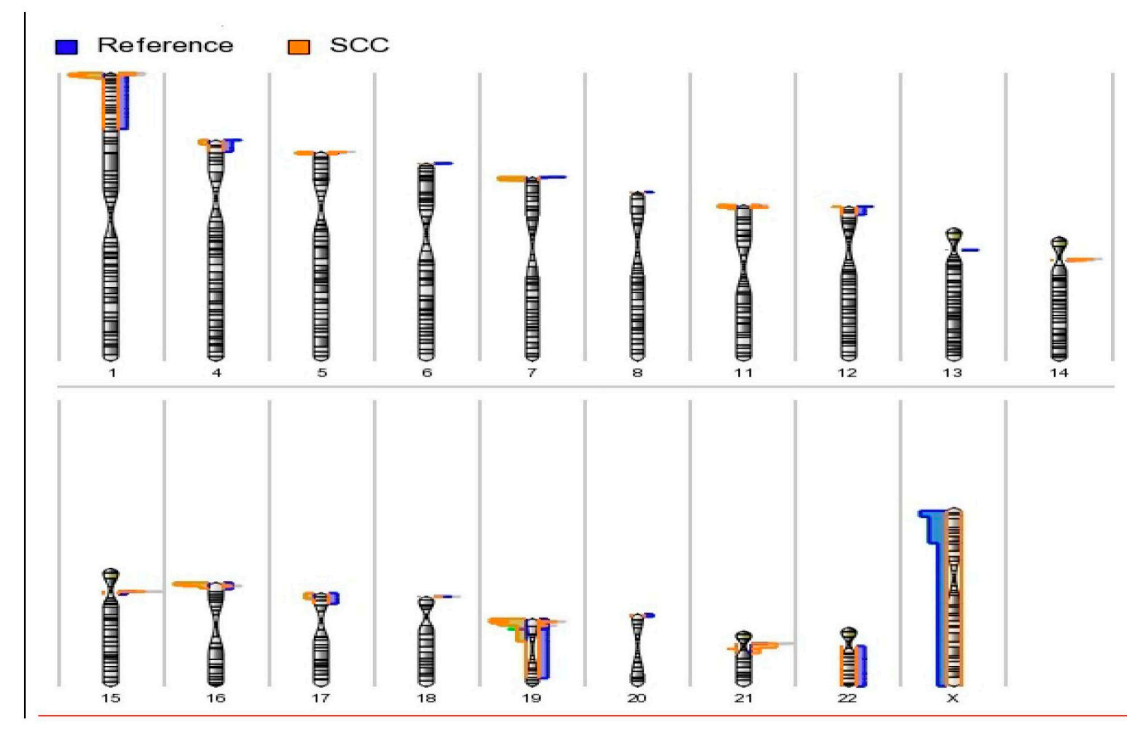

Figure 1. Karyogram view of detected amplified and deleted regions across autosomes. Amplifications are shown at right side of the chromosomes, and deletions are shown at the left side of the chromosomes. The length of the horizontal bar corresponds to the number of samples observed at the respective cytobands. Most of the amplifications were found in cases at the short arms of chromosomes 1, 5, $8,16,19$ and 20, as well as the centromeres of chromosomes 14, 15 and 21. Most of the deletions in the cases were mainly observed at the short arms of chromosomes 1, 4, 5, 7, 11, 12, 16, 17 and 19, as well as the centromere of chromosome 19 . We observed a statistically-significant difference of CNA burden between case and reference groups (Table 2) for different sizes of CNAs (>100 kb, 10-100 kb and 1-10 kb). For example, statistically-significant differences of $>100 \mathrm{~kb}, 10-100 \mathrm{~kb}$ and 1-10 kb deletions were observed between reference $(6.7 \%, 2.5 \%, 0.8 \%)$, pre-cancer $(92.5 \%, 81.5 \%, 87.7 \%)$ and cancer $(89.0 \%, 76.7 \%, 86.6 \%)$ groups, respectively (Table 2$)$. 
Table 2. Copy number alteration (CNA) burden (deletion and amplification) among different diagnostic groups.

\begin{tabular}{|c|c|c|c|c|c|c|c|c|c|c|c|c|}
\hline \multicolumn{13}{|l|}{$2 \mathrm{~A}$} \\
\hline \multirow[t]{2}{*}{ Size of CNAs } & \multicolumn{3}{|c|}{ Reference $(n=122)$} & \multicolumn{3}{|c|}{ Low $(n=4)$} & \multicolumn{3}{|c|}{ High $(n=5)$} & \multicolumn{3}{|c|}{$\operatorname{SCC}(n=5)$} \\
\hline & All & $\begin{array}{l}\text { Amplification } \\
(\%)\end{array}$ & $\begin{array}{l}\text { Deletion } \\
(\%)\end{array}$ & All & $\begin{array}{l}\text { Amplification } \\
(\%)\end{array}$ & $\begin{array}{l}\text { Deletion } \\
(\%)\end{array}$ & All & $\begin{array}{l}\text { Amplification } \\
(\%)\end{array}$ & $\begin{array}{l}\text { Deletion } \\
(\%)\end{array}$ & All & Amplificati & $\begin{array}{c}\text { n Deletion } \\
(\%)\end{array}$ \\
\hline$>100 \mathrm{~kb}$ & 212 & $198(93.3)$ & $14(6.7)$ & 156 & $15(9.6)$ & $141(90.4)$ & 244 & $15(6.1)$ & $229(93.9)$ & 218 & $24(11)$ & $194(89)$ \\
\hline $10-100 \mathrm{~kb}$ & 157 & $153(97.5)$ & $4(2.5)$ & 119 & $24(20.2)$ & $95(79.8)$ & 183 & $32(17.5)$ & $151(82.5)$ & 163 & $38(23.3)$ & $125(76.7)$ \\
\hline $1 \mathrm{~kb}-10 \mathrm{~kb}$ & 128 & 127 (99.2) & $1(0.8)$ & 125 & $11(8.8)$ & $114(91.2)$ & 193 & $28(14.5)$ & $165(85.5)$ & 179 & $24(13.4)$ & 155 (86.6) \\
\hline \multicolumn{13}{|l|}{$2 \mathrm{~B}$} \\
\hline Size of CNAs & \multicolumn{3}{|c|}{ Reference } & \multicolumn{3}{|c|}{ Pre-Cancer $(n=9)$} & \multicolumn{6}{|c|}{ Cancer $(n=5)$} \\
\hline & All & \multicolumn{2}{|c|}{$\begin{array}{c}\text { Amplification Deletion } \\
(\%)\end{array}$} & All & \multicolumn{2}{|c|}{$\begin{array}{c}\text { Amplification Deletion } \\
(\%)\end{array}$} & \multicolumn{2}{|r|}{ All } & \multicolumn{2}{|c|}{ Amplification (\%) } & \multicolumn{2}{|c|}{ Deletion (\%) } \\
\hline$>100 \mathrm{~kb}$ & 212 & $198(93.3)$ & $14(6.7)$ & 400 & $30(7.5)$ & $370(92.5)$ & \multicolumn{2}{|r|}{218} & \multicolumn{2}{|c|}{$24(11)$} & \multicolumn{2}{|c|}{$194(89.0)$} \\
\hline $10-100 \mathrm{~kb}$ & 157 & $153(97.5)$ & $4(2.5)$ & 302 & $56(18.5)$ & $246(81.5)$ & \multirow{2}{*}{\multicolumn{2}{|c|}{$\begin{array}{l}163 \\
179\end{array}$}} & \multicolumn{2}{|c|}{38 (23.3) } & \multicolumn{2}{|c|}{125 (76.7) } \\
\hline $1 \mathrm{~kb}-10 \mathrm{~kb}$ & 128 & 127 (99.2) & $1(0.8)$ & 318 & 39 (12.3) & $279(87.7)$ & & & \multicolumn{2}{|c|}{$24(13.4)$} & \multicolumn{2}{|c|}{$155(86.6)$} \\
\hline
\end{tabular}


The chromosomal locations of the copy number amplifications and deletions of the 22 autosomes and $X$ chromosomes were shown by karyograms (Figure 1). Most of the amplifications are found in the cases at the short arms of chromosomes 1,5,8,16,19 and 20, as well as the centromeres of chromosomes 14, 15 and 21. Most of the deletions in the cases were mainly observed at the short arms of chromosomes 1, 4, 5, 7,11,12,16, 17 and 19, as well as the centromeres of chromosome 19.

\subsection{Principal Component Analysis (PCA)}

To characterize aberration profiles in different diagnostic groups (low grade dysplasia, high grade dysplasia, SCC and reference), we performed a PCA (Figure 2). There was a great variability in the three diagnostic groups (reference, pre-cancer and cancer) and four diagnostic groups (reference, low grade, high grade and SCC). These results indicate that there is a distinct difference in the patterns of the CNAs between case and reference groups based on the genomic profiles of these subjects.
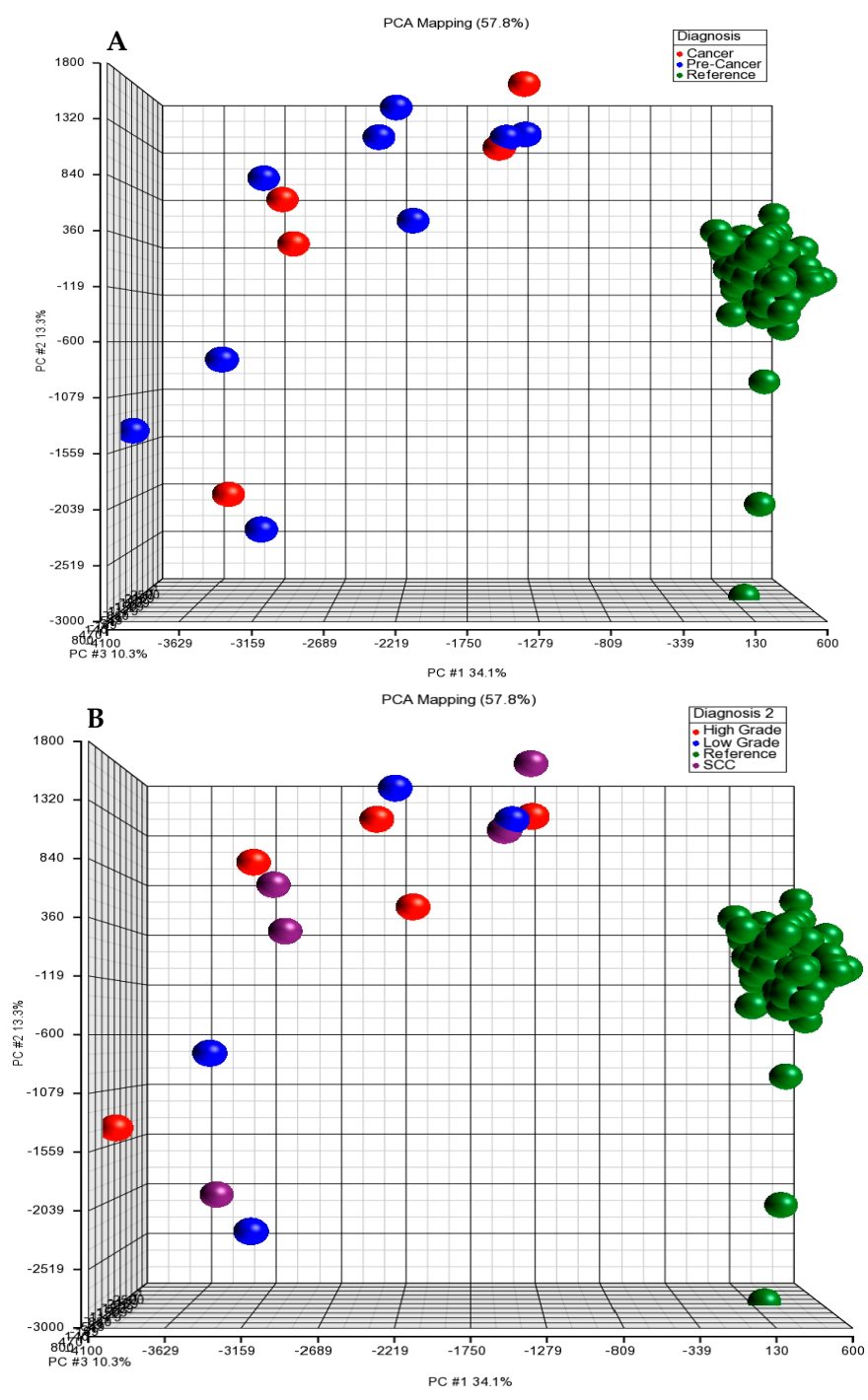

Figure 2. Plot of principal component analysis (PCA) and hierarchical clustering of copy number variation (CNV) or CNA datasets. (A) PCA scatter plot of three diagnostic groups (pre-cancer, cancer and reference). Each point represents a specific sample. Points are colored by group status, with blue representing pre-cancer (CIN-I, -II and -III), red representing invasive cancer and green representing references. (B) PCA scatter plot of four diagnostic groups. Each point represents a specific sample. Points are colored by group status, with blue representing low grade (CIN-I), red representing high grade (CIN- II and -III), purple representing invasive cancer and green representing references. 
Overall, there was a clear separation between the reference and the case group when examined by PCA clustering.

\subsection{Genome-Wide CNA and Cancer Progression}

Increasing evidence demonstrates that more numerical genomic alterations are associated with progression from precursor lesions to invasive cancer [25]. Thus, we conducted CNA genomic analysis in different diagnostic groups to understand the complexities of the genomic architecture of these highly heterogeneous groups of cervical cancer and to assess whether CNA burden impacts the prognosis of cervical cancer in this Mexican American population. We analyzed CNAs among two (pre-cancer and cancer; Table 2B) and three diagnostic groups (low grade, high grade and SCC; Table 2A) in cases only. There was no statistically-significant difference of CNA burden among diagnostic groups in cases in any size of CNA, although there are slightly higher frequencies of amplifications in the $100 \mathrm{~kb}, 10-100 \mathrm{~kb}$ and $1-10 \mathrm{~kb}$ categories in the cancer group (11.0\%, $23.3 \%$ and $13.4 \%$, respectively) as compared to the pre-cancer group $(7.5 \%, 18.5 \%$ and $12.3 \%$, respectively) (Table 2$)$ using 205 two-tailed $\chi^{2}$ tests with the SPSS statistical software package.

\subsection{Recurrent Aberrations Identified in Cases Only}

We are interested in recurrent CNAs since the chromosome regions with recurrent CNAs more likely to harbor disease-critical genes are those that show alterations that are recurrent among individuals with cancer or other diseases [26,27]. In this context, we can define a recurrent CNA region as a set of contiguous genes (a region) that shows a high enough probability (or evidence) of being altered (e.g., deletion or insertion) in two or more samples, as previously described [28]. The recurrent aberrations in a total of $98 \mathrm{CNA}$ regions containing 849 genes/loci were identified only in the case group (pre-cancer and cancer subjects) with at least two cases who carried these CNAs. None of these CNAs were observed in the reference group (Table 3). Among these 98 recurrent CNA regions, there were 545 deletions (84\%) and 104 amplifications (16\%) observed in cases only using statistical analyses described in the Methods section.

Table 3 shows the top 20 chromosome regions with a high number of recurrent somatic CNAs $(>100 \mathrm{~kb})$ in the cases with at least nine subjects carrying these deletions in each CNA region; none of these CNAs were observed in the reference group. Some of the CNAs contain tumor suppressor genes (e.g., axis inhibition protein 1 (AXIN1) and tuberous sclerosis complex 2 (TSC2)).

Eight exceptionally large CNA regions with deletions of between $1591 \mathrm{~kb}$ and $517 \mathrm{~kb}$ were detected in cases on short arms of chromosomes 1,16 and 19.

In addition to recurrent deletions identified in the cases (Table 3), two recurrent CNA regions with a $220-\mathrm{kb}$ amplification on $21 \mathrm{q} 11.2$ and a $113.5-\mathrm{kb}$ deletion on $7 \mathrm{p} 22.2$ were observed in only CIN-III and SCC.

Next, we checked the Cervical Cancer Database (CCDB) [29] and found three genes, haemoglobin alpha 2 (HBA2), mesothelin (MSLN) and STK11, overlapped between 849 genes/loci observed from our current study and 538 genes listed in the CCDB. 
Table 3. Top 20 CNA chromosome regions with recurrent somatic CNAs (deletions $>100 \mathrm{~kb}$ ) in the cases; not observed in the reference group.

\begin{tabular}{|c|c|c|c|c|c|c|c|}
\hline Cytoband & Start & Stop & \# of Sub. with Del*. & Deletions in Subjects & No. of Markers & Length (bp) & Cancer-Related Genes \\
\hline 19p13.3 & 766,463 & $2,357,625$ & 10 & I (2), II (1), III (3), SCC (4) & 1497 & $1,591,163$ & STK11 \\
\hline $19 \mathrm{p} 13.3$ & $2,860,429$ & $3,984,025$ & 10 & I (2), II (1), III (3), SCC (4) & 1154 & $1,123,597$ & MATK, DAPK3 \\
\hline $16 \mathrm{p} 13.3$ & 895,986 & $1,883,511$ & 10 & I (2), II (1), III (3), SCC (4) & 1022 & 987,526 & AXIN1 \\
\hline $19 \mathrm{p} 13.3$ & $3,984,025$ & $4,738,536$ & 9 & I (2), II (1), III (3), SCC (3) & 672 & 754,512 & \\
\hline $1 \mathrm{p} 36.33-1 \mathrm{p} 36.32$ & $1,825,510$ & $2,545,368$ & 9 & I (2), II (0), III (3), SCC (4) & 732 & 719,859 & HES5 \\
\hline $1 \mathrm{p} 36.32$ & $2,545,368$ & $3,230,848$ & 9 & I (2), II (0), III (3), SCC (4) & 678 & 685,481 & PRDM16 \\
\hline $16 \mathrm{p} 13.3$ & 377,287 & 895,986 & 10 & I (2), II (1), III (3), SCC (4) & 525 & 518,700 & AXIN1, MSLN \\
\hline $1 \mathrm{p} 36.33$ & $1,282,654$ & $1,799,975$ & 9 & I (2), II (0), III (3), SCC (4) & 242 & 517,322 & \\
\hline 16 p13.3 & $2,816,699$ & $3,271,935$ & 8 & I (2), II (0), III (3), SCC (3) & 469 & 455,237 & BSG, FGF22, AXIN1 \\
\hline $7 \mathrm{p} 22.3$ & 93,965 & 534,503 & 8 & I (2), II (0), III (3), SCC (3) & 265 & 440,539 & \\
\hline $19 \mathrm{p} 13.3$ & 366,342 & 762,497 & 10 & I (2), II (1), III (3), SCC (4) & 604 & 396,156 & HBA2 \\
\hline $16 \mathrm{p} 13.3$ & $2,408,963$ & $2,706,379$ & 8 & I (2), II (0), III (3), SCC (3) & 142 & 297,417 & \\
\hline $16 \mathrm{p} 13.3$ & 84,130 & 377,287 & 10 & I (2), II (1), III (3), SCC (4) & 284 & 293,158 & AXIN1 \\
\hline $16 \mathrm{p} 13.3$ & $2,132,651$ & $2,397,391$ & 10 & I (2), II (1), III (3), SCC (4) & 141 & 264,741 & TSC2 \\
\hline $1 \mathrm{p} 36.33$ & $1,021,380$ & $1,282,654$ & 9 & I (2), II (0), III (3), SCC (4) & 233 & 261,275 & \\
\hline $16 \mathrm{p} 13.3$ & $1,888,316$ & $2,115,231$ & 10 & I (2), II (1), III (3), SCC (4) & 210 & 226,916 & \\
\hline $1 \mathrm{p} 36.33$ & 810,836 & $1,021,380$ & 9 & I (2), II (0), III (3), SCC (4) & 221 & 210,545 & \\
\hline $19 \mathrm{p} 13.3$ & $2,532,493$ & $2,735,499$ & 10 & I (2), II (1), III (3), SCC (4) & 228 & 203,007 & \\
\hline $19 \mathrm{p} 13.3$ & $2,367,858$ & $2,532,493$ & 10 & I (2), II (1), III (3), SCC (4) & 191 & 164,636 & \\
\hline $19 \mathrm{p} 13.3$ & 254,506 & 365,334 & 10 & I (2), II (1), III (3), SCC (4) & 108 & 110,829 & \\
\hline
\end{tabular}

\# of Sub. with Del *: number of subjects with deletion. Serine/threonine kinase 11 (STK11); maturase K (MATK); Death-associated protein kinase 3 (DAPK3); axis inhibition protein 1 (AXIN1); hairy/enhancer of split, drosophila, homolog of, 5 (HES5); PR domain containing 16 (PRDM16); mesothelin (MSLN); basignin (BSG); fibroblast growth factor 22 (FGF22); haemoglobin A2 (HBA2); tuberous sclerosis complex 2 (TSC2). 
3.5. CNA Regions Contained Known Tumor Suppressor Genes and Oncogenes in Cancer Tissues but Not in the Reference Group

We were also interested in identifying CNA regions that were observed only in cases and over $100 \mathrm{~kb}$ containing known cancer-related genes as compared to the references (Tables 3-5). Thus, we examined whether newly-identified CNAs contained tumor suppressor genes and/or oncogenes. We observed a total of 26 CNA regions containing known tumor suppressor gene regions. These CNAs were deletions and only seen in the case group. Furthermore, none of these regions were observed in the reference group (Table 4). We also observed a total of six CNA regions with deletions (no amplification) containing known oncogenes in the case group, and none of these regions were observed in the reference group (Table 5).

Table 4. Newly-identified CNAs (deletions) contain known oncogenes in cases only.

\begin{tabular}{ccccc}
\hline \multicolumn{1}{c}{ Query Position } & Gene Name & Gene ID & Length (bp) & Deletions in Different Diagnostic Groups \\
\hline chr4:1694786-1937978 & WHSC1 & 7468 & 243,193 & ref (0), I (1), II (0), III (3), SCC (1) \\
chr4:1937978-2141625 & WHSC1 & 7468 & 203,648 & ref (0), I (1), II (0), III (3), SCC (1) \\
chr19:6194240-6239714 & MLLT1 & 4298 & 45,475 & ref (0), I (2), II (0), III (2), SCC (1) \\
chr19:6239714-6598484 & MLLT1 & 4298 & 358,771 & ref (0), I (2), II (0), III (2), SCC (1) \\
chr19:6679537-6796128 & VAV1 & 7409 & 116,592 & ref (0), I (2), II (0), III (1), SCC (1) \\
chr19:6796128-6883617 & VAV1 & 7409 & 87,490 & ref (0), I (2), II (0), III (1), SCC (1) \\
\hline
\end{tabular}

Wolf-Hirschhorn syndrome candidate 1 (WHSC1); myeloid/lymphoid leukemia; translocated to 1 (MLLT1); vav guanine nucleotide exchange factor 1 (VAV1).

Table 5. Newly-identified CNAs (deletions) contain known tumor suppressor genes in cases only.

\begin{tabular}{|c|c|c|c|c|}
\hline Query Position & Gene Name & $\begin{array}{l}\text { Gene } \\
\text { ID }\end{array}$ & $\begin{array}{l}\text { Length } \\
\text { (bp) }\end{array}$ & $\begin{array}{l}\text { Deletions in Different } \\
\text { Diagnostic Groups }\end{array}$ \\
\hline chr1:3252272-3613519 & TP73 & 7161 & 361,248 & ref (0), I (1), II (0), III (3), SCC (3) \\
\hline chr1:3613519-3615102 & TP73 & 7161 & 1584 & ref (0), I (1), II (0), III (3), SCC (3) \\
\hline chr1:3615102-3615341 & TP73 & 7161 & 240 & $\operatorname{ref}(0), \mathrm{I}(1), \mathrm{II}(0), \mathrm{III}(3), \operatorname{SCC}(3)$ \\
\hline chr1:3615341-3621322 & TP73 & 7161 & 5982 & ref (0), I (1), II (0), III (3), SCC (3) \\
\hline chr1:3621322-4125280 & TP73 & 7161 & 503,959 & ref (0), I (1), II (0), III (2), SCC (2) \\
\hline chr5:204517-422812 & $A H R R$ & 57491 & 218,296 & ref (0), I (1), II (0), III (3), SCC (2) \\
\hline chr5:422812-582058 & AHRR & 57491 & 159,247 & ref (0), I (1), II (0), III (3), SCC (2) \\
\hline chr7:1216332-1963055 & MAD1L1 & 8379 & 746,724 & ref (0), I (2), II (0), III (3), SCC (3) \\
\hline chr7:1963055-1964889 & $M A D 1 L 1$ & 8379 & 1835 & ref (0), I (2), II (0), III (3), SCC (3) \\
\hline chr7:1964889-2219927 & MAD1L1 & 8379 & 255,039 & ref (0), I (2), II (0), III (3), SCC (3) \\
\hline chr7:2219927-2770642 & MAD1L1 & 8379 & 550,716 & ref (0), I (2), II (0), III (3), SCC (3) \\
\hline chr16:1888316-2115231 & TSC2 & 7249 & 226,916 & ref (0), I (2), II (1), III (3), SCC (4) \\
\hline chr16:2115231-2116240 & TSC2 & 7249 & 1010 & ref (0), I (2), II (1), III (3), SCC (4) \\
\hline chr16:2116240-2127184 & TSC2 & 7249 & 10,945 & ref (0), I (2), II (1), III (3), SCC (4) \\
\hline chr16:2127184-2132651 & TSC2 & 7249 & 5468 & ref (0), I (2), II (1), III (3), SCC (4) \\
\hline chr16:2132651-2397391 & TSC2 & 7249 & 264,741 & ref (0), I (2), II (1), III (3), SCC (4) \\
\hline chr16:377287-895986 & AXIN1 & 8312 & 518,700 & ref (0), I (2), II (1), III (3), SCC (4) \\
\hline chr16:84130-377287 & AXIN1 & 8312 & 293,158 & ref (0), I (2), II (1), III (3), SCC (4) \\
\hline chr17:1586256-1692127 & SMYD4 & 114826 & 105,872 & ref (0), I (1), II (0), III (3), SCC (1) \\
\hline chr17:1692127-1737406 & SMYD4 & 114826 & 45,280 & ref (0), I (1), II (0), III (3), SCC (1) \\
\hline chr19:5310257-5598484 & $S A F B 2$ & 9667 & 288,228 & $\operatorname{ref}(0), \mathrm{I}(2), \mathrm{II}(0), \mathrm{III}(3), \operatorname{SCC}(3)$ \\
\hline chr19:5598484-5623377 & SAFB2 & 9667 & 24,894 & ref (0), I (2), II (0), III (3), SCC (3) \\
\hline chr19:5598484-5623377 & $S A F B$ & 6294 & 24,894 & $\operatorname{ref}(0), \mathrm{I}(2), \mathrm{II}(0), \mathrm{III}(3), \operatorname{SCC}(3)$ \\
\hline chr19:5623377-5625242 & $S A F B$ & 6294 & 1,866 & ref (0), I (2), II (0), III (3), SCC (3) \\
\hline chr19:5625242-5625729 & $S A F B$ & 6294 & 488 & ref (0), I (2), II (0), III (3), SCC (3) \\
\hline chr19:5625729-5846816 & $S A F B$ & 6294 & 221,088 & ref (0), I (2), II (0), III (3), SCC (3) \\
\hline
\end{tabular}

Reference (0), I (1), II (0), III (3), SCC (3) means a 361-kb deletion on chromosome 1 occurred in one subject with CIN-I, 3 subjects with CIN-III and 3 subjects with SCC. 


\subsection{Pathway Analysis}

Recent studies have incorporated protein networks into the results of genome-wide CNA data using networks or GO analysis to discover disease-associated and/or enriched pathways [30-33]. Therefore, we conducted GO analysis and Kyoto Encyclopedia of Genes and Genomes (KEGG) pathway analysis.

The results of the functional enrichment of KEGG pathway analysis in the identified CNAs $>100 \mathrm{~kb}$ that occurred in two or more cases are shown in Table 6 . Fourteen pathways were discovered, including the insulin signaling pathway and the endometrial cancer and estrogen signaling pathway, with enrichment $p$ values lower than 0.05 . A GO analysis was performed by selecting CNAs in the genes to see if any GO categories were overrepresented among CNAs identified in cases [34]. Many biological processes were undisturbed at the molecular level, while others were frequently affected across multiple cases, as shown in Table 7, which lists the most commonly-affected function with $p$-values lower than 0.05 and more than four genes in each function category.

Table 6. Functional enrichment of Kyoto Encyclopedia of Genes and Genomes (KEGG) pathway analysis in the identified CNAs (>100 kb and occurring in two or more patients with SCC).

\begin{tabular}{|c|c|c|c|c|c|}
\hline Pathway Name & $\begin{array}{c}\text { Enrichment } \\
\text { Score }\end{array}$ & $\begin{array}{l}\text { Enrichment } p \\
\text { Value }\end{array}$ & $\begin{array}{c}\text { \% Genes in } \\
\text { Pathway }\end{array}$ & \# Gene in List & $\begin{array}{c}\text { KEGG } \\
\text { Pathway ID }\end{array}$ \\
\hline Insulin signaling pathway & 4.749 & 0.009 & 7.03 & 9 & 16 \\
\hline Endometrial cancer & 4.698 & 0.009 & 10.64 & 5 & 11 \\
\hline Parkinson's disease & 4.054 & 0.017 & 7.22 & 7 & 215 \\
\hline Glioma & 3.713 & 0.024 & 8.33 & 5 & 182 \\
\hline Huntington's disease & 3.640 & 0.026 & 5.84 & 9 & 52 \\
\hline NF- $\kappa B$ signaling & 3.572 & 0.028 & 7.14 & 6 & 163 \\
\hline Ribosome & 3.522 & 0.030 & 7.06 & 6 & 275 \\
\hline Alcoholism & 3.495 & 0.030 & 5.70 & 9 & 191 \\
\hline Neurotrophin signaling pathway & 3.399 & 0.033 & 6.31 & 7 & 50 \\
\hline Estrogen signaling pathway & 3.326 & 0.036 & 6.75 & 6 & 154 \\
\hline RNA polymerase & 3.195 & 0.041 & 10.71 & 3 & 238 \\
\hline Dopaminergic synapse & 3.042 & 0.048 & 5.83 & 7 & 20 \\
\hline PI3K-Akt signaling pathway & 3.038 & 0.048 & 4.52 & 14 & 262 \\
\hline Ubiquitin-mediated proteolysis & 3.005 & 0.049 & 5.79 & 7 & 175 \\
\hline
\end{tabular}

$\# \geqslant 6$ genes in each function were listed here.

Table 7. Gene ontology (GO) categories of CNAs (>100 kb and occurring in two or more than two patients with SCC).

\begin{tabular}{|c|c|c|c|c|c|c|}
\hline Type & Function & $\begin{array}{l}\text { Enrichment } \\
\text { Score }\end{array}$ & $\begin{array}{c}\text { Enrichment } \\
p \text { Value }\end{array}$ & $\begin{array}{l}\% \text { Genes } \\
\text { in Group }\end{array}$ & $\begin{array}{l}\text { \# Genes } \\
\text { in List }\end{array}$ & GO ID \\
\hline \multirow[t]{5}{*}{ Molecular function } & signal transducer activity & 5.344 & 0.005 & 0.477 & 7 & 4871 \\
\hline & molecular transducer activity & 4.780 & 0.008 & 0.430 & 7 & 60089 \\
\hline & enzyme binding & 3.089 & 0.046 & 0.376 & 5 & 19899 \\
\hline & protein kinase binding & 5.858 & 0.003 & 0.998 & 4 & 19901 \\
\hline & kinase binding & 5.405 & 0.004 & 0.879 & 4 & 19900 \\
\hline \multirow[t]{6}{*}{ Cellular component } & membrane-bounded vesicle & 4.420 & 0.012 & 0.338 & 9 & 31988 \\
\hline & vesicle & 4.193 & 0.015 & 0.326 & 9 & 31982 \\
\hline & plasma membrane & 3.061 & 0.047 & 0.271 & 9 & 5886 \\
\hline & plasma membrane part & 3.388 & 0.034 & 0.328 & 7 & 44459 \\
\hline & plasma membrane protein complex & 5.500 & 0.004 & 0.903 & 4 & 98797 \\
\hline & membrane protein complex & 3.203 & 0.041 & 0.457 & 4 & 98796 \\
\hline \multirow[t]{9}{*}{ Biological process } & signal transduction & 4.648 & 0.010 & 0.291 & 12 & 7165 \\
\hline & cell surface receptor signaling pathway & 4.546 & 0.011 & 0.344 & 9 & 7166 \\
\hline & regulation of signal transduction & 3.443 & 0.032 & 0.332 & 7 & 9966 \\
\hline & positive regulation of gene expression & 3.992 & 0.018 & 0.413 & 6 & 10628 \\
\hline & macromolecular complex subunit organization & 3.303 & 0.037 & 0.354 & 6 & 43933 \\
\hline & G-protein coupled receptor signaling pathway & 4.089 & 0.017 & 0.489 & 5 & 7186 \\
\hline & negative regulation of response to stimulus & 3.821 & 0.022 & 0.457 & 5 & 48585 \\
\hline & defense response & 3.783 & 0.023 & 0.452 & 5 & 6952 \\
\hline & positive regulation of protein metabolic process & 3.569 & 0.028 & 0.428 & 5 & 51247 \\
\hline
\end{tabular}




\section{Discussion}

It has been demonstrated that somatic structural alterations (e.g., amplifications or deletions) of human chromosomes represent a common class of mutations, which may cause gene disruption (e.g., deletion or rearrangement), gene activation (e.g., CNAs, gain or amplification) or the formation of novel oncogenic gene products (gene fusions). Many of these events actively drive carcinogenesis $[35,36]$. In our initial cervical cancer cohort, some CNA patterns identified were previously found to be correlated with cervical cancer.

We screened whole genomes with 2.5 million markers of an array to discover any recurrent copy number alterations in cases (pre-cancer and SCC). We identified a total of $98 \mathrm{CNA}$ regions $>100 \mathrm{~kb}$ in the case group, including low grade dysplasia, high grade dysplasia and SCC. These CNAs occurred in two or more cases, including two large deletions (1591 kb and $1123 \mathrm{~kb}$ ) (Table 3). Of the top 20 CNA regions $>100 \mathrm{~kb}$ deletions in cases only, six CNAs occurred on 16p13 that have been reported in cervical cancer [37], and mutation analysis of the AXIN1 gene located at 16p13 was reported to be involved in the Wnt pathway in cervical carcinomas [38]. The CNA containing the SET and MYND domain-containing protein 4 (SMYD4) gene on 17p13.3 was also reported previously in this cancer [37]. The SMYD4 gene is demonstrated to be a potential tumor suppressor and plays a critical role in breast carcinogenesis, at least partly through inhibiting the expression of platelet-derived growth factor receptor-alpha (PDGFRA), and this gene could be a novel target for improving the treatment of breast cancer [39].

A number of previous studies demonstrate that numerical chromosomal aberrations were found to progress to invasive cancer from precursor lesions [25,37]; however, we did not observe this feature in our current study sample. This might be due to the small sample size or any other unknown or not yet identified factors, such as ethnicity, since most previous study populations are non-Hispanic populations.

Among two amplifications identified in CIN-III and SCC, one recurrent CNA region with a 220-kb amplification on 21q11.2 was observed in CIN-III and co-occurred with previous findings, where the amplification had been identified in breast cancer subjects with tamoxifen resistance [40].

The recurrent CNA regions we identified contain a number of tumor suppressor genes, oncogenes and cancer-related genes. A CNA that contains the interferon-induced transmembrane protein 1 (IFITM1) gene at 11p15.5 was identified in eight cases. This gene has been reported to be involved in cervical carcinogenesis [41]. A total of nine cases with the CNA containing the fucosyltransferase 3 (FUT3) gene at 19p13.3 were observed in the current study, and this gene is associated with breast cancer [42]. A CNA region that includes the naked cuticle 2 (NKD2) gene at 5p15.35 was detected in six cases. This gene was found to suppress breast cancer proliferation by inhibiting Wnt signaling [43]. The ovarian cancer-associated gene 2 protein (OVCA2) at $17 \mathrm{p} 13.3$ was repeatedly reported to be associated with ovarian cancer, and we observed five cases carrying the CNA at this gene region. A cluster of three tumor suppressor genes, cadherin 1 (CDH1), death-associated protein kinase (DAPK) and hypermethylated in cancer 1 (HIC1), displayed a significantly increased frequency of promoter methylation with progressively more severe cervical neoplasia. In addition, the Hes family BHLH Transcription Factor 5 (HES5) gene was reported to be associated with cervical carcinoma cells using immunocytochemistry, Western blot and methyl thiazolyl tetrazolium assays [44], and the CNAs on 1p36.33-1p36.32 containing the HES5 gene were also identified in the current study. Our newly-identified CNA containing this gene on 7p22.2 was also observed in the recurrent pre-cancer and cancer subjects (Table 3).

Moreover, we also examined deletion burden observed to be similar to those for other cancers and found more deletions identified than amplification in most of the cancer studies, which supports our findings. A recent study using the TCGA data identified nine regions of deletion that were unique to estrogen receptor positive (ER+) post menopause tumors in patients with breast cancer [45], including deletion in 7p22.3, where our newly-identified deletion in cases only was located, and it contains a known tumor suppressor gene. 
To analyze the possible effect of genomic alterations, to further capture cancer-causing gene information and to see whether any GO categories are overrepresented among CNA regions, we searched the KEGG pathway database and GO categories and identified a number of pathways and functions where CNAs occur in the SCC group, but not in the reference group (Tables 6 and 7). Furthermore, our results were partly in agreement with previous reports about cervical cancer. For example, using the functional enrichment of KEGG pathway analysis, we discovered the insulin signaling pathway in the case group, and it was evidenced that HPV 16 E6 oncoprotein interferes with the insulin signaling pathway by binding to tuberin [46]. As is already known, high-risk HPV infection is a causal agent for cervical cancer. In addition, two pathways of interest are endometrial cancer and the estrogen signaling pathway observed in the current study. The NF- $\kappa B$ signaling pathway was also identified in our cancer group (SCC), but not in the reference group, which supports a previous study where bisphenol A (BPA) stimulated the cervical cancer migration via IKK- $\beta$ /NF- $\mathrm{kB}$ signals [47]. The estrogen signaling pathway was also shown in our KEGG analysis. A previous study was performed to evaluate the potential of miRNAs as novel markers for the post-therapeutic monitoring of cervical SCC patients. A regulatory network of differentially-expressed serum miRNAs was identified, and a number of target genes was predicted in the estrogen-mediated signal pathways [48]. Ours and others' findings support that cervical cancer is a hormone-associated gynecological disease. For example, HPV infection has been associated with the deregulation of the PI3K-Akt-mTOR pathway in invasive cervical carcinomas [49]. The PI3K-Akt signaling pathway was also found in our current study, and 14 genes in this pathway were found in two or more SCC cases (Table 6).

Moreover, signal transducer activity with an enrichment score of 4.2 and a $p$ value of 0.01 containing 11 genes was also identified in a previous report on cervical cancer [50] using GO analysis. Signal transduction was identified in our current study in cervical cancer (SCC), but not in the reference group; a recent study also supports that a signal transduction cascade and mitogen-activated protein kinase kinase kinase 3 (MEKK3) serve as key integration points and are important factors in regulating cellular responses to environmental stress. This signal transduction and MEKK3 not only link diverse extracellular stimuli to subsequent signaling molecules, but they also amplify the initiating signals to ultimately activate effector molecules and induce cell proliferation, differentiation and survival of cervical cancer [51].

These pathways and functions were identified as overlapping biological themes, and these data may provide useful information on the molecular mechanisms for cervical cancer, its prognosis and treatment responses.

There are a number of novelties in this study: (1) this is the first report of CNAs in the relatively ethnically homogeneous group of Mexican Americans using high density mapping (2.5 million in number); previous studies using less density markers may result in an underestimation of the genetic changes that take place in cervical cancer; (2) newly-identified CNAs in cases together with results in the in silico analysis using KEGG and GO function provide insight into how multiple CNAs might contribute to cervical cancer development. We also are aware of some limitations in our study. (1) Our small sample size (14 cases and 125 references) is a major limitation for this type of study. Due to a small number of samples, the nature of genome-wide alteration of copy number may not be fully explained in pre-cancer and SCC. Future confirmation studies using an independent sample will provide an opportunity to more accurately dissect the genetic complexity of somatic CNAs for cervical cancer. (2) There might be a bias of the CNA identified in cervical cancer for the Mexican Americans, since we used the 1000 Genome admixed populations, not Mexican Americans; thus, we currently are recruiting more subjects with cervical cancer from the same population and plan to validate the findings in more samples. (3) Other biomarkers, such as RNA-Seq or DNA methylation profile and sequencing data using next generation sequencing technologies (such as target gene sequencing in these CNA regions), will provide an opportunity for in-depth molecular profiling of the fundamental biological processes of cervical cancer. 
We expect that with future validation and confirmation, newly-discovered CNAs can be used in cancer classification, diagnosis, prognosis and treatment responses.

\section{Conclusions}

Using high density SNP array analysis, we have shown extensive genome-wide CNA changes in pre-cancer and cancer groups as compared to the genome CNA profile in the reference group. Our results demonstrated that the recurrent alterations of CNAs occurred in cases of pre-cancer and SCC. Some of the somatic genomic gains and losses in cervical pre-cancer and cancer were in concordance with the results from previous studies. To our knowledge, no previous studies have applied genome-wide copy number analysis using such high density markers for cervical cancers in the Mexican American population; however, validation and confirmation in a larger sample size are needed.

Acknowledgments: We are grateful to all of the subjects who participated in the study and the many dedicated oncologists at TTUHSC and local hospitals in El Paso for help in patient ascertainment. Thanks are given to Arun Joseph for assisting with part of the data analysis. This study was supported, in part, by the TTUHSC Seed grant (PI, Chun $\mathrm{Xu}$ ) and the TTUHSC Mini grant (PI, Chun $\mathrm{Xu}$ ).

Author Contributions: Alireza Torabi provided tissue samples and conceived and designed the experiments. Javier Ordonez performed the experiments and offered data analysis ( $\mathrm{CNV}$ analysis and bioinformatics analysis). Brenda Bin Su was involved in bioinformatics analysis and wrote the paper. Laura Palmer made a contribution to the data analysis. Chuanxiong Mao made a contribution to the data analysis and manuscript revision. Katherine E. Lara made a contribution to the data mining and data analysis. Lewis P. Rubin made a contribution to part of the manuscript and offered critical comments and suggestions on this paper. Chun $\mathrm{Xu}$, as PI, designed the study, supervised the others and wrote the paper.

Conflicts of Interest: The authors declare no conflict of interest.

\section{References}

1. Jemal, A.; Bray, F.; Center, M.M.; Ferlay, J.; Ward, E.; Forman, D. Global cancer statistics. CA Cancer J. Clin. 2011, 61, 69-90. [CrossRef] [PubMed]

2. Green, J.; Berrington de Gonzalez, A.; Sweetland, S.; Beral, V.; Chilvers, C.; Crossley, B.; Deacon, J.; Hermon, C.; Jha, P.; Mant, D.; et al. Risk factors for adenocarcinoma and squamous cell carcinoma of the cervix in women aged 20-44 years: The UK national case-control study of cervical cancer. Br. J. Cancer 2003, 89, 2078-2086. [CrossRef] [PubMed]

3. Pisani, P.; Bray, F.; Parkin, D.M. Estimates of the world-wide prevalence of cancer for 25 sites in the adult population. Int. J. Cancer 2002, 97, 72-81. [CrossRef] [PubMed]

4. Termini, L.; Maciag, P.C.; Soares, F.A.; Nonogaki, S.; Pereira, S.M.; Alves, V.A.; Longatto-Filho, A.; Villa, L.L. Analysis of human kallikrein 7 expression as a potential biomarker in cervical neoplasia. Int. J. Cancer 2010, 127, 485-490. [CrossRef] [PubMed]

5. Lockwood, W.W.; Coe, B.P.; Williams, A.C.; MacAulay, C.; Lam, W.L. Whole genome tiling path array CGH analysis of segmental copy number alterations in cervical cancer cell lines. Int. J. Cancer 2007, 120, 436-443. [CrossRef] [PubMed]

6. Yu, K.J.; Rader, J.S.; Borecki, I.; Zhang, Z.; Hildesheim, A. CD83 polymorphisms and cervical cancer risk. Gynecol. Oncol. 2009, 114, 319-322. [CrossRef] [PubMed]

7. Ma, D.; Hovey, R.L.; Zhang, Z.; Fye, S.; Huettner, P.C.; Borecki, I.B.; Rader, J.S. Genetic variations in EGFR and ERBB4 increase susceptibility to cervical cancer. Gynecol. Oncol. 2013, 131, 445-450. [CrossRef] [PubMed]

8. Cancer Facts and Figures for Hispanics/Latinos 2009-2011; American Cancer Society: Atlanta, GA, USA, 2009; Available online: http://www.cancer.org/acs/groups/content/@nho/documents/document/ ffhispanicslatinos20092011.pdf (accessed on 24 July 2016).

9. McDougall, J.A.; Madeleine, M.M.; Daling, J.R.; Li, C.I. Racial and ethnic disparities in cervical cancer incidence rates in the United States, 1992-2003. Cancer Causes Control 2007, 18, 1175-1186. [CrossRef] [PubMed] 
10. Xu, C.; Blackburn, A.N.; Gonzalez, S.; Villa, E.C.; Ramirez, M.; Zavala, J.; Rodriguez, M.; Camarillo, C.; Ordonez, J.; Armas, R.; et al. Rare Copy Number Variants in Schizophrenia and Bipolar Disorder in a Latino Population; American Society of Human Genetics: San Francisco, CA, USA, 2012.

11. Zhang, F.; Gu, W.; Hurles, M.E.; Lupski, J.R. Copy number variation in human health, disease, and evolution. Annu. Rev. Genom. Hum. Genet. 2009, 10, 451-481. [CrossRef] [PubMed]

12. Lupski, J.R. Structural variation in the human genome. New Engl. J. Med. 2007, 356, 1169-1171. [CrossRef] [PubMed]

13. Redon, R.; Ishikawa, S.; Fitch, K.R.; Feuk, L.; Perry, G.H.; Andrews, T.D.; Fiegler, H.; Shapero, M.H.; Carson, A.R.; Chen, W.; et al. Global variation in copy number in the human genome. Nature 2006, 444, 444-454. [CrossRef] [PubMed]

14. McCarroll, S.A.; Kuruvilla, F.G.; Korn, J.M.; Cawley, S.; Nemesh, J.; Wysoker, A.; Shapero, M.H.; de Bakker, P.I.; Maller, J.B.; Kirby, A.; et al. Integrated detection and population-genetic analysis of SNPs and copy number variation. Nat. Genet. 2008, 40, 1166-1174. [CrossRef] [PubMed]

15. Iafrate, A.J.; Feuk, L.; Rivera, M.N.; Listewnik, M.L.; Donahoe, P.K.; Qi, Y.; Scherer, S.W.; Lee, C. Detection of large-scale variation in the human genome. Nat. Genet. 2004, 36, 949-951. [CrossRef] [PubMed]

16. Inaki, K.; Liu, E.T. Structural mutations in cancer: Mechanistic and functional insights. Trends Genet. 2012, 28, 550-559. [CrossRef] [PubMed]

17. Crook, T.; Wrede, D.; Tidy, J.A.; Mason, W.P.; Evans, D.J.; Vousden, K.H. Clonal p53 mutation in primary cervical cancer: Association with human-papillomavirus-negative tumours. Lancet 1992, 339, 1070-1073. [CrossRef]

18. McIntyre, J.B.; Wu, J.S.; Craighead, P.S.; Phan, T.; Kobel, M.; Lees-Miller, S.P.; Ghatage, P.; Magliocco, A.M.; Doll, C.M. PIK3CA mutational status and overall survival in patients with cervical cancer treated with radical chemoradiotherapy. Gynecol. Oncol. 2013, 128, 409-414. [CrossRef] [PubMed]

19. Narayan, G.; Murty, V.V. Integrative genomic approaches in cervical cancer: Implications for molecular pathogenesis. Future Oncol. 2010, 6, 1643-1652. [CrossRef] [PubMed]

20. Vazquez-Mena, O.; Medina-Martinez, I.; Juarez-Torres, E.; Barron, V.; Espinosa, A.; Villegas-Sepulveda, N.; Gomez-Laguna, L.; Nieto-Martinez, K.; Orozco, L.; Roman-Basaure, E.; et al. Amplified genes may be overexpressed, unchanged, or downregulated in cervical cancer cell lines. PLoS ONE 2012, 7, e32667. [CrossRef] [PubMed]

21. http://hapmap.ncbi.nlm.nih.gov/downloads/samplesindividuals/00README.txt (accessed on 23 May 2016).

22. Chanda, P.; Yuhki, N.; Li, M.; Bader, J.S.; Hartz, A.; Boerwinkle, E.; Kao, W.H.; Arking, D.E. Comprehensive evaluation of imputation performance in African Americans. J. Hum. Genet. 2012, 57, 411-421. [CrossRef] [PubMed]

23. Massink, M.P.; Kooi, I.E.; van Mil, S.E.; Jordanova, E.S.; Ameziane, N.; Dorsman, J.C.; van Beek, D.M.; van der Voorn, J.P.; Sie, D.; Ylstra, B.; et al. Proper genomic profiling of (BRCA1-mutated) basal-like breast carcinomas requires prior removal of tumor infiltrating lymphocytes. Mol. Oncol. 2015, 9, 877-888. [CrossRef] [PubMed]

24. Ali Hassan, N.Z.; Mokhtar, N.M.; Kok Sin, T.; Mohamed Rose, I.; Sagap, I.; Harun, R.; Jamal, R. Integrated analysis of copy number variation and genome-wide expression profiling in colorectal cancer tissues. PLOS ONE 2014, 9, e92553. [CrossRef]

25. Alazawi, W.; Pett, M.; Strauss, S.; Moseley, R.; Gray, J.; Stanley, M.; Coleman, N. Genomic imbalances in 70 snap-frozen cervical squamous intraepithelial lesions: Associations with lesion grade, state of the HPV16 E2 gene and clinical outcome. Br. J. Cancer 2004, 91, 2063-2070. [CrossRef] [PubMed]

26. Pinkel, D.; Albertson, D.G. Array comparative genomic hybridization and its applications in cancer. Nat. Genet. 2005, 37, 11-17. [CrossRef] [PubMed]

27. Misra, A.; Pellarin, M.; Nigro, J.; Smirnov, I.; Moore, D.; Lamborn, K.R.; Pinkel, D.; Albertson, D.G.; Feuerstein, B.G. Array comparative genomic hybridization identifies genetic subgroups in grade 4 human astrocytoma. Clin. Cancer Res. 2005, 11, 2907-2918. [CrossRef] [PubMed]

28. Rueda, O.M.; Diaz-Uriarte, R. Detection of recurrent copy number alterations in the genome: Taking among-subject heterogeneity seriously. BMC Bioinform. 2009, 10, 308. [CrossRef] [PubMed]

29. http://crdd.osdd.net/raghava/ccdb/faq.php (accessed on 16 October 2015). 
30. Emily, M.; Mailund, T.; Hein, J.; Schauser, L.; Schierup, M.H. Using biological networks to search for interacting loci in genome-wide association studies. Eur. J. Hum. Genet. 2009, 17, 1231-1240. [CrossRef] [PubMed]

31. Pan, W. Network-based model weighting to detect multiple loci influencing complex diseases. Hum. Genet. 2008, 124, 225-234. [CrossRef] [PubMed]

32. Baranzini, S.E.; Galwey, N.W.; Wang, J.; Khankhanian, P.; Lindberg, R.; Pelletier, D.; Wu, W.; Uitdehaag, B.M.; Kappos, L.; Polman, C.H.; et al. Pathway and network-based analysis of genome-wide association studies in multiple sclerosis. Hum. Mol. Genet. 2009, 18, 2078-2090. [CrossRef] [PubMed]

33. Correia, C.; Oliveira, G.; Vicente, A.M. Protein interaction networks reveal novel autism risk genes within GWAS statistical noise. PLoS ONE 2014, 9, e112399. [CrossRef] [PubMed]

34. Holmans, P.; Green, E.K.; Pahwa, J.S.; Ferreira, M.A.; Purcell, S.M.; Sklar, P.; Owen, M.J.; O’Donovan, M.C.; Craddock, N. Gene ontology analysis of gwa study data sets provides insights into the biology of bipolar disorder. Am. J. Hum. Genet. 2009, 85, 13-24. [CrossRef] [PubMed]

35. Stephens, P.J.; Greenman, C.D.; Fu, B.; Yang, F.; Bignell, G.R.; Mudie, L.J.; Pleasance, E.D.; Lau, K.W.; Beare, D.; Stebbings, L.A.; et al. Massive genomic rearrangement acquired in a single catastrophic event during cancer development. Cell 2011, 144, 27-40. [CrossRef] [PubMed]

36. Stephens, P.J.; McBride, D.J.; Lin, M.L.; Varela, I.; Pleasance, E.D.; Simpson, J.T.; Stebbings, L.A.; Leroy, C.; Edkins, S.; Mudie, L.J.; et al. Complex landscapes of somatic rearrangement in human breast cancer genomes. Nature 2009, 462, 1005-1010. [CrossRef] [PubMed]

37. Oh, E.K.; Kim, Y.W.; Kim, I.W.; Liu, H.B.; Lee, K.H.; Chun, H.J.; Park, D.C.; Oh, E.J.; Lee, A.W.; Bae, S.M.; et al. Differential DNA copy number aberrations in the progression of cervical lesions to invasive cervical carcinoma. Int. J. Oncol. 2012, 41, 2038-2046. [PubMed]

38. Su, T.H.; Chang, J.G.; Yeh, K.T.; Lin, T.H.; Lee, T.P.; Chen, J.C.; Lin, C.C. Mutation analysis of CTNNB1 (beta-catenin) and AXIN1, the components of Wnt pathway, in cervical carcinomas. Oncol. Rep. 2003, 10, 1195-1200. [PubMed]

39. Hu, L.; Zhu, Y.T.; Qi, C.; Zhu, Y.J. Identification of Smyd4 as a potential tumor suppressor gene involved in breast cancer development. Cancer Res. 2009, 69, 4067-4072. [CrossRef] [PubMed]

40. Achuthan, R.; Bell, S.M.; Roberts, P.; Leek, J.P.; Horgan, K.; Markham, A.F.; MacLennan, K.A.; Speirs, V. Genetic events during the transformation of a tamoxifen-sensitive human breast cancer cell line into a drug-resistant clone. Cancer Genet. Cytogenet. 2001, 130, 166-172. [CrossRef]

41. Pan, Z.; Chen, S.; Pan, X.; Wang, Z.; Han, H.; Zheng, W.; Wang, X.; Li, F.; Qu, S.; Shao, R. Differential gene expression identified in Uigur women cervical squamous cell carcinoma by suppression subtractive hybridization. Neoplasma 2010, 57, 123-128. [CrossRef] [PubMed]

42. Kolbl, A.C.; Hiller, R.A.; Ilmer, M.; Liesche, F.; Heublein, S.; Schroder, L.; Hutter, S.; Friese, K.; Jeschke, U.; Andergassen, U. Glycosyltransferases as marker genes for the quantitative polymerase chain reaction-based detection of circulating tumour cells from blood samples of patients with breast cancer undergoing adjuvant therapy. Mol. Med. Rep. 2015, 12, 2933-2938. [PubMed]

43. Dong, Y.; Cao, B.; Zhang, M.; Han, W.; Herman, J.G.; Fuks, F.; Zhao, Y.; Guo, M. Epigenetic silencing of NKD2, a major component of wnt signaling, promotes breast cancer growth. Oncotarget 2015, 6, 22126-22138. [CrossRef] [PubMed]

44. Liu, J.; Lu, W.G.; Ye, F.; Cheng, X.D.; Hong, D.; Hu, Y.; Chen, H.Z.; Xie, X. Hes1/Hes5 gene inhibits differentiation via down-regulating Hash1 and promotes proliferation in cervical carcinoma cells. Int. J. Gynecol. Cancer 2010, 20, 1109-1116. [CrossRef] [PubMed]

45. Liao, S.; Hartmaier, R.J.; McGuire, K.P.; Puhalla, S.L.; Luthra, S.; Chandran, U.R.; Ma, T.; Bhargava, R.; Modugno, F.; Davidson, N.E.; et al. The molecular landscape of premenopausal breast cancer. Breast Cancer Res. 2015, 17, 104. [CrossRef] [PubMed]

46. Lu, Z.; Hu, X.; Li, Y.; Zheng, L.; Zhou, Y.; Jiang, H.; Ning, T.; Basang, Z.; Zhang, C.; Ke, Y. Human papillomavirus $16 \mathrm{E} 6$ oncoprotein interferences with insulin signaling pathway by binding to tuberin. J. Biol. Chem. 2004, 279, 35664-35670. [CrossRef] [PubMed]

47. Ma, X.F.; Zhang, J.; Shuai, H.L.; Guan, B.Z.; Luo, X.; Yan, R.L. IKK $\beta / N F-\kappa \beta$ mediated the low doses of bisphenol A induced migration of cervical cancer cells. Arch. Biochem. Biophys. 2015, 573, 52-58. [CrossRef] [PubMed] 
48. Wang, W.T.; Zhao, Y.N.; Yan, J.X.; Weng, M.Y.; Wang, Y.; Chen, Y.Q.; Hong, S.J. Differentially expressed microRNAs in the serum of cervical squamous cell carcinoma patients before and after surgery. J. Hematol. Oncol. 2014, 7, 6. [CrossRef] [PubMed]

49. Tinker, A.V.; Ellard, S.; Welch, S.; Moens, F.; Allo, G.; Tsao, M.S.; Squire, J.; Tu, D.; Eisenhauer, E.A.; MacKay, H. Phase II study of temsirolimus (CCI-779) in women with recurrent, unresectable, locally advanced or metastatic carcinoma of the cervix. A trial of the NCIC Clinical Trials Group (NCIC CTG IND 199). Gynecol. Oncol. 2013, 130, 269-274. [CrossRef] [PubMed]

50. Kuo, J.H.; Lin, C.W. Cellular uptake on N- and C-termini conjugated FITC of Rath cell penetrating peptides and its consequences for gene-expression profiling in U-937 human macrophages and HeLa cervical cancer cells. J. Drug Target. 2013, 21, 801-808. [CrossRef] [PubMed]

51. Cao, X.Q.; Lu, H.S.; Zhang, L.; Chen, L.L.; Gan, M.F. MEKK3 and survivin expression in cervical cancer: Association with clinicopathological factors and prognosis. Asian Pac. J. Cancer Prev. APJCP 2014, 15, 5271-5276. [CrossRef] [PubMed]

(C) 2016 by the authors; licensee MDPI, Basel, Switzerland. This article is an open access article distributed under the terms and conditions of the Creative Commons Attribution (CC-BY) license (http://creativecommons.org/licenses/by/4.0/). 